\title{
Measuring Environmental Attitudes and Behaviors
}

This chapter ${ }^{1}$ discusses the basis of our approach, situating it in the existing research on environmental attitudes and behaviors and presenting related scales and surveys. First, the concepts of environmental attitudes and behaviors are discussed with a special emphasis on behavior that has an impact on the environment. Subsequently, the key empirical findings on the factors shaping these attitudes and behaviors will be presented. Afterward, we describe the measurement variants of these dimensions. In particular, the focus is on the measurement of environmental attitudes and behaviors in surveys and on the sub-dimension of emissions-related behavior, which has rarely been included in social science surveys. Finally, obstacles to the inclusion of emission-relevant questions in the survey context are identified.

\subsection{Environmental Attitudes and Behaviors}

There is not one single definition of environmental attitudes that is generally accepted. Some approaches see environmental attitudes as a unidimensional construct. Gifford and Sussman (2012) for example, define environmental attitudes as a "concern for the environment or caring about environmental issues" (p. 65). Their focus is on the emotional attachment to nature and an associated sense of worry. Other approaches emphasize the multidimensional nature of environmental attitudes and often

\footnotetext{
${ }^{1}$ Lead author: Markus Schweighart.
}

(C) The Author(s) 2022 
distinguish between the affective (corresponds to emotional involvement, i.e., concern), the cognitive (environmental knowledge), and the conative (behavioral intention) dimensions (Maloney \& Ward, 1973; Diekmann \& Preisendörfer, 1998). The concept of environmental attitudes is broader in the latter approaches since the level of knowledge and the level of behavioral intentions are also seen as part of the attitudes.

One of the most influential approaches is the work of William Catton and Riley Dunlap (1978). They consider different environmental attitudes as expressions of one underlying worldview and proposed a concept of an environmental sociology, which focuses on the interaction between the environment and society. They argue that no matter how different sociological theories were, they all shared as a common characteristic an anthropocentric worldview - that is, humans were always emphasized as unique beings standing above nature. Because of the great importance of culture, which can consciously be adapted and changed, the belief in the human ability to solve social, technical and thus ecological problems is deeply rooted in this dominant way of thinking. The authors labeled this perspective the Human Exceptionalism Paradigm (HEP) and believed that it is the reason why sociology struggles to deal with the social implications of ecological problems. The authors thus proposed the New Environmental Paradigm (NEP), which emphasizes the inseparable connection of humans with nature and the limits of the physical and biological world.

Alongside environmental attitudes, social research is interested in measuring environmental behavior. Anja Kollmuss and Julian Agyeman (2002) understand environmental behavior as "behavior that strives to minimize the negative impact of one's own actions on the natural environment" (p. 214). It thus comprises a variety of practices, such as measures to reduce energy consumption, waste avoidance, restrictions on the purchasing consumer goods, and conscious choice of transport but also compensation payments for flights or participation in environmental protest campaigns.

A basic distinction can be made between public- and private-sphere environmental behaviors (Stern, 2000). Behaviors that affect the publicsphere range from environmental activism, such as protest and direct actions, to less intense forms, such as participation in petitions or the vote for a green political party. The goal of this type of behavior is to point out problems and to motivate decision makers (in politics and business) and other citizens to act in an ecologically responsible manner. Private-sphere behavior, in contrast, includes personal environment-related behaviors 
and refers to individual actions with the goal to reduce one's personal impact on the environment or mitigate the negative environmental consequences of one's own lifestyle.

Furthermore, when measuring energy and resource consumption, a distinction is often made between direct and indirect energy use (Benders et al., 2006). Direct energy use refers to the direct energy consumption that is used for heating the living space, electricity, and operating motorized vehicles. Indirect energy use, alternatively, refers to the energy consumption required for the production, distribution, and waste disposal of consumer goods and services.

Brigitta Gatersleben et al. (2002) emphasize that environmentally friendly behavior is often defined by researchers based on popular notions of environmentally significant behavior (pro environmental behavior) rather than on impact. Recycling, for example, is undoubtedly environmentoriented behavior, but compared to other behaviors, it does have a rather small impact in terms of energy consumption or greenhouse gas (GHG) emissions (Wynes \& Nicholas, 2017). ${ }^{2}$ Andreas Diekmann and Peter Preisendörfer (1998) note that certain behaviors are surveyed because they are understood as cognitive proxies for environmental behavior in general. Turning off the light when leaving a room is here a prominent example. However, in the case of such typical environmental behaviorsuch as switching off lights, separating waste, or saving water-the actual effect on the environment in terms of energy consumption or emissions is often minor.

Some of these problems arise from the definition of environmental behavior we encountered above. Focusing on behavior that strives to reduce the negative impact on nature means that the will to do something good for the environment is more important than the actual consequences. Hence, Paul Stern (2000) emphasizes the important distinction between environmental intent and environmental impact. This fundamental

\footnotetext{
${ }^{2}$ However, one might argue that this depends on the definition of impact. This is true, as it is not too difficult to find contexts, in which a lack of recycling leads to severe pollution and accompanying problems. For example, when waste is deposited in landfills, serious problems often arise, not only in terms of the environment, but also in social and political terms. One only has to think of electric waste dumps in African countries, which poison valuable groundwater and at the same time represent a precarious means of existence for many children and families and look for copper (see, e.g., Perkins et al., 2014). But from the perspective applied in this book, namely the GHG emission perspective on impact, recycling is still not that important.
} 
distinction calls for another important definition-the meaning of negative impact. Negative impact on the environment can be the pollution of air and water and shrinking natural habitats but also direct interferences in the ecosystem such as hunting and fishing.

Against the background of the urgent problem of climate change, impact in this work refers to the GHGs emitted that are directly and indirectly associated with behavior and energy consumption. Building on this, the differentiation between general environmental behavior (intention oriented) and emission-relevant environmental behavior (impact oriented) is crucial. General environmental behavior is based more on the intention to do something good for the environment and usually covers many areas of behavior. Emission-relevant environmental behavior concentrates only on those areas in which the highest levels of GHG emissions occur.

\subsection{Factors Influencing Environmental Attitudes AND BEHAVIORS}

\section{Environmental Attitudes}

After presenting the basic concepts of environmental attitudes and behaviors, we now turn to the central explanatory factors. Generally, the influence of socio-demographic determinants on different aspects of environmental attitudes is rather weak-with an explained variance of below 20\% (Klineberg et al., 1998). However, studies suggest there are significant effects of some socio-demographic characteristics (Dunlap \& Jones, 2002; Zelezny et al., 2000; Grønhøj \& Ölander, 2007). The results show that gender, age, and education level significantly influence environmental awareness in such a way that younger and better-educated individuals are characterized by a higher level of environmental awareness. An explanation for the gender effect may be found in social gender role models, in which women tend to be socialized to be empathetic and nurturing, whereas men are socialized to be more competitive and materialistic. Greater empathy and a stronger concern for others also affect how we deal with the environment. Furthermore, it has been shown that a liberal political attitude tends to be related to a higher environmental concern (Marquart-Pyatt, 2008; Van Liere \& Dunlap, 1981; Samdahl \& Robertson, 1989). 


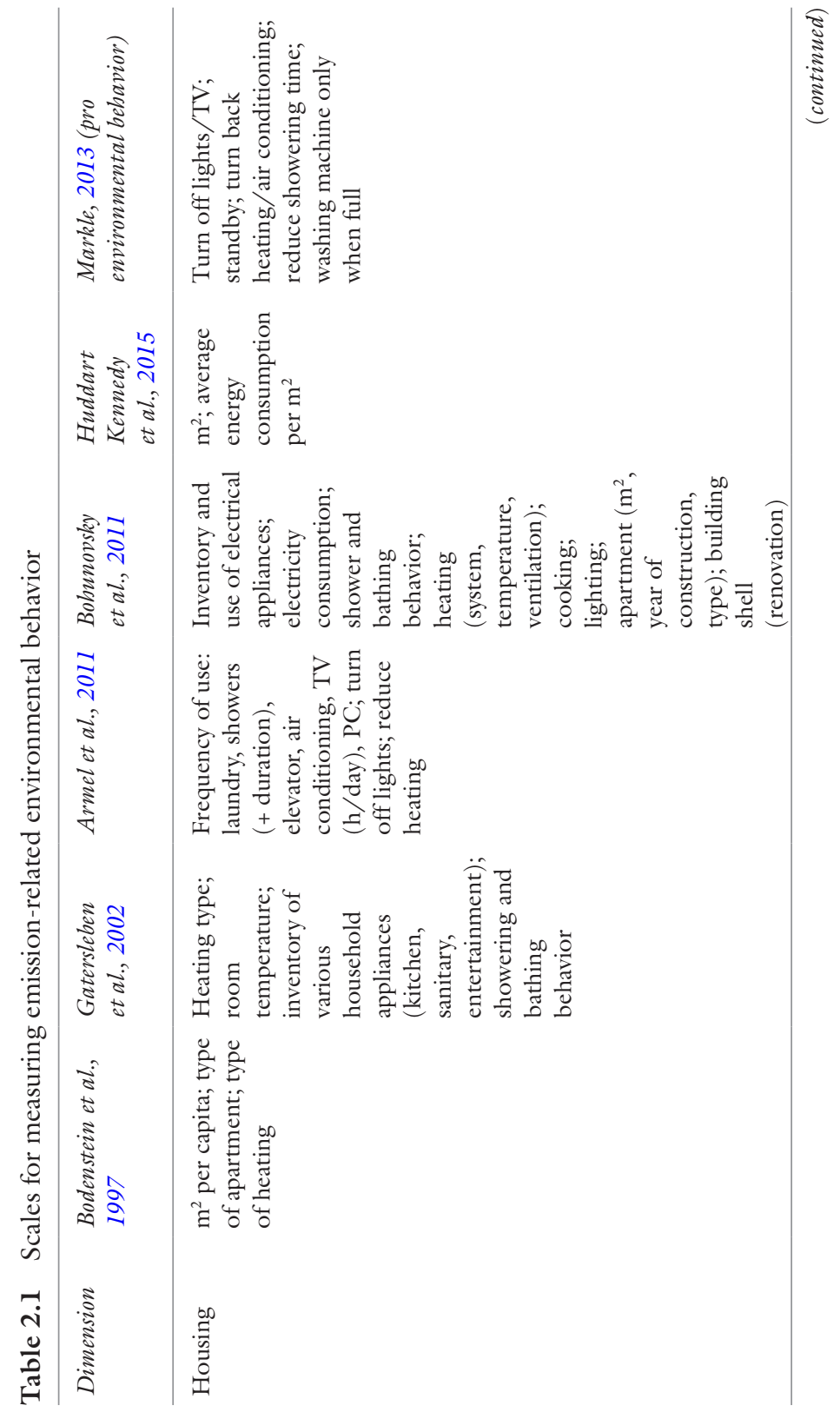


M. HADLER ET AL.

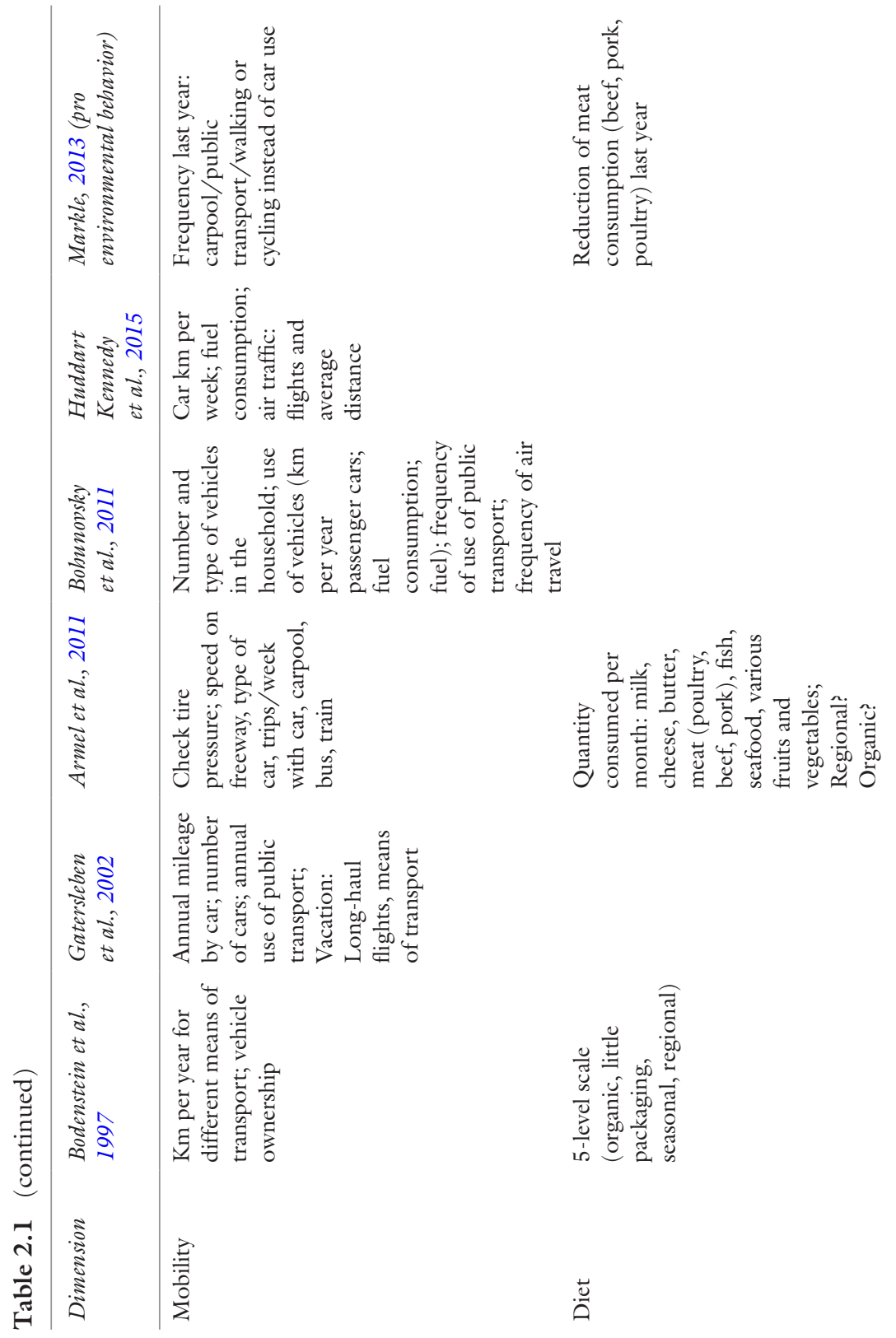



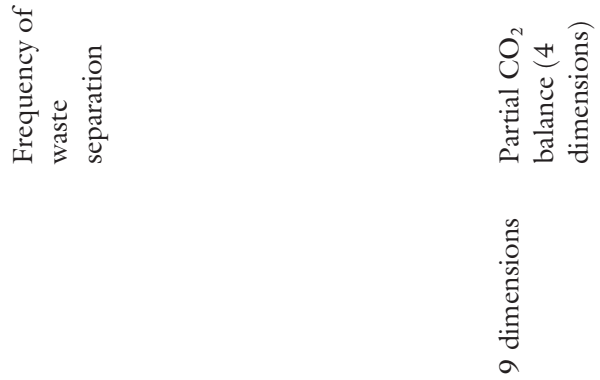

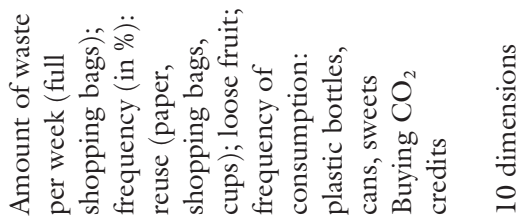

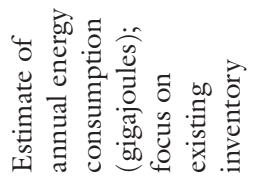

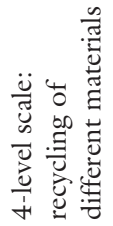

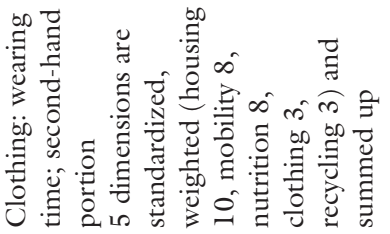

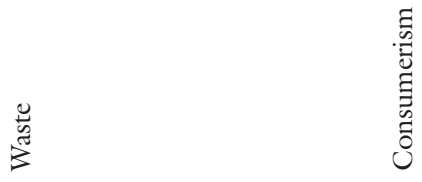


As for the cross-national comparison of environmental attitudes, the most studied topics are the influences of affluence and of post-materialistic values. Based on Ronald Inglehart's (1997) approach, in which postmaterial values lead to environmental concern, a debate arose in the scientific field. Facing empirical evidence, Inglehart later included severe environmental degradation as an explanatory factor, which is often found in poorer countries as a source of environmental concern (Inglehart, 1997). The mutual influences of levels of affluence, post-materialism, and objective environmental pollution have not been resolved sufficiently. The studies carried out for this purpose, which came to partly contradictory results, used very different data, models, and measurements (MarquartPyatt, 2008). Results based on multilevel analysis show that environmental concern is higher in poorer countries but that within countries, more affluent people are slightly more concerned about the environment (Fairbrother, 2013).

\section{General Environmental Behavior}

According to an influential paper by Kollmuss and Agyeman (2002), a general distinction should be made between internal and external factors when explaining environmental behaviors. External, or contextual, factors include infrastructure; the political, legal, and economic situation; and social and cultural factors. As for internal factors, the most influential theoretical approaches come from psychology. Stern (2011) further distinguishes psychological theories in approaches that are based on individualistic motives and those that place more emphasis on social norms. The former are variations of rational choice concepts, such as the Theory of Planned Behavior (Ajzen, 1991), which focuses on behavioral costs and on personal utility. In contrast, the value-belief-norm theory (Stern et al., 1999) and the norm-activation model (Schwartz, 1977) point out that environmental behavior is motivated pro-socially. Bamberg and Möser (2007) show in a meta-analysis that individualistic motives (e.g., attitudes, problem awareness, and perceived behavioral control) as well as social norms are significant independent predictors of environmental behavior. Different studies supplement these psychologically grounded determinants with contextual aspects, such as behavioral abilities (Gatersleben et al., 2002), opportunity structures (Hadler \& Haller, 2011), behavioral costs (Diekmann \& Preisendörfer, 1998), dwelling characteristics (Perkins et al., 2014), and different settings (at home, at work, etc.; Bratt et al., 
2015). Additionally, some macro-level factors such as wealth, urbanization, and level of post-materialism (Pisano \& Lubell, 2017) also turn out to be influential in this regard.

Moreover, some studies highlight the influence of socio-demographic attributes such as age, sex, and income, and of attitudes and values (Diekmann \& Jann, 2000; Dunlap et al., 2000; Huddart Kennedy et al., 2015; Gatersleben et al., 2002; Lenzen et al., 2004; Pisano \& Lubell, 2017). Results indicate that women show more and stronger environmentally friendly behavior. Findings on age are less consistent as some works have found more environmentally friendly behaviors amongst older people, whilst others found no such effect. A higher income does not affect general environmental behavior (but it comes along with a higher energy demand and GHG emissions, as we will see later). Finally, Bratt et al. (2015) show that some private environmental behaviors (i.e., home-based actions) are strongly correlated with impression management scales. Individuals who are interested in impressing their counterparts show stronger environmentally friendly behaviors.

\section{Emission-Related Environmental Behavior}

"Emission relevance" refers to a specific type of environmental behavior. However, studies have found that a single socio-demographic characteristic has the greatest influence here, namely income. People with higher incomes show increased levels of emissions based on their behavior (Huddart Kennedy et al., 2015; Csutora, 2012). The reasons for this are certainly that many individual emission-related behaviors are highly routine actions (diet, commuting), that they are subject to restrictions that limit one's choices (housing), or that they fall into domains with strong emotions involved, such as mobility, traveling, or diet. The latter examples, while also emissions-related aspects of life, are even more so resources or vehicles for constructing self-identity - and they are a form of social communication (Ehrhardt-Martinez et al., 2015).

Stern (2000) also points out that many environmentally relevant behaviors are part of personal routines and/or are subject to severe restrictions such as lack of infrastructure or financial resources. Based on the idea that behavior is influenced by attitudes, on the one hand, and by context, on the other hand, Stern hypothesizes that with the increasing environmental impact of a behavior, the dependence on attitudes decreases. This is similar to the high-cost hypothesis (Diekmann \& Preisendörfer, 1998), which 
postulates that situations involving high behavioral costs (such as choice of transport) must be clearly distinguished from those involving low behavioral costs (e.g., recycling). The influences of attitudes and values can therefore only be effective in the area of low behavioral costs. The influence of social networks (offline and online) on emission-relevant behavior has also been determined, for example, using the example of nutrition (Christakis \& Fowler, 2007).

Altogether, contextual factors and basic conditions explain more of the variance in energy-relevant behavior than do individual features (Newton \& Meyer, 2012; Tabi, 2013). Within individual determinants, sociodemographics are stronger predictors for actual consumption (Poortinga et al., 2004), while attitudes are more important when it comes to changing behaviors (Abrahamse \& Steg, 2009). It is evident that a strictly individualistic approach is insufficient in explaining environmental behavior since structural effects and contextual conditions are important. Geographical conditions; political, historical, and institutional frameworks; and structural contexts have to be considered as well. In some cases, these contextual situations can be realized by studying country specifics. In particular, infrastructure, laws and regulations, financial incentives, the price level of various behavioral offerings, the state of the national economy, and cultural and social norms should be examined, following established suggestions (Kollmuss \& Agyeman, 2002; Stern, 2000). International comparative studies are particularly interesting and challenging in this regard as possible differences can also be attributed to these factors along with all the other potentially influencing factors.

This brief summary shows the complexity of emission-related behaviors and general environmental behaviors. Even more, the relation of these two variants of environmental behavior to environmental attitudes also differs. Environmentally friendly attitudes correlate with general environmental behavior, whereas there is no impact on energy demand and emission-based measures (Huddart Kennedy et al., 2015). This moderate correlation notwithstanding, gaps between environmental attitudes and general behaviors - known as the value-action gap (Blake, 1999)—and between environmental behaviors and the actual ecological consequences of actions-known as behavior-impact gap (Csutora, 2012)—occur frequently. We will address these gaps in Chap. 7. 


\subsection{Measuring Environmental Attitudes}

In empirically oriented sociology, the study of environmental issues dates back to the 1970s. Since then, dealing with environment-related attitudes has become the basis of empirical environmental social science research (Huddart Kennedy et al., 2015), and measuring attitudes, in conjunction with socio-demographic characteristics, accounts for a large proportion of the research conducted to date (Dunlap et al., 2000; Stern, 2000; Knight \& Messer, 2012).

A pioneering piece of research was Michael Maloney and Michael Ward's (1973) psychological study, which used 130 questions to investigate verbal willingness to act ecologically, emotional involvement with environmental problems and environmental knowledge. It thus covered all aspects of the tripartite attitude measurement (see Best, 2011). Subsequently, a variant of this measurement tradition gained great importance in the German-speaking part of the world-the scale for measuring general environmental behavior by Andreas Diekmann and Peter Preisendörfer (1998). Recently, criticism of this tripartite division has increased, and reductions or differentiations have been proposed and developed (Schaffrin, 2011). For example, the cognitive dimension is said to differ from the other dimensions and should rather be treated as their precondition (Bord et al., 2000).

Based on the original NEP concept mentioned before, Riley Dunlap together with Kent van Liere (1978) developed an enhanced item set to measure attitude dimensions, which they called the New Environmental Paradigm. The authors claim that the ecological worldview is onedimensional and measurable with their scale. An overview of the frequent reuse of this scale and its variants can be found in Lucy Hawcroft and Taciano Milfont (2010). The most prominent evolution of the original scale was done by the original authors themselves together with Angela Mertig and Robert Emmet Jones (Dunlap et al., 2000). This new scale adds further facets of an ecological worldview and comprises a set of 15 items representing both pro and counter positions with a strong internal consistency.

These two measurement traditions of environmental attitudes presented above have dominated the research and evoked a number of follow-up studies. Regardless, several other, completely new measuring instruments have also been developed. The development of ever-new scales has been criticized as it has resulted in a multitude of different 
operationalizations without proper theoretical foundations (Dunlap \& Jones, 2002). An overview of such scales including a critical evaluation is provided by André Schaffrin (2011). Our focus here is on behaviors; hence, we will devote more space to this aspect in the following section.

\subsection{Measuring Environmental Behavior}

The measurement of environmental behavior has been carried out using a variety of scales consisting of different items, which often only refer to specific aspects of environmentally relevant behavior and do not claim to be able to comprehensively measure it (Markle, 2013). In the following, we will first deal with those measurement variants that are aiming at general environmental behavior and then with those that refer to emissionrelevant behavior. The latter are often found in more technically oriented studies that investigate specific behaviors in detail, often relying on technical measurement appliances (e.g., metering electricity consumption or using GPS devices to track mobility). At the same time, often the causal factors, such as attitudes, values, or context, are only poorly captured in these studies and thus do not provide any information about factors that can be helpful to foster behavioral change. At the other end of the spectrum, there are social scientific surveys that are more strongly oriented toward values, attitudes, and behavioral intentions, and thus only allow limited conclusions to be drawn about actual behavior let alone quantifiable emission amounts.

Looking at scales for measuring general environmental behavior, one finds a wide range of behavioral domains. Such scales cover different areas and include hypothetical behaviors, such as a willingness to give up driving or pay higher taxes for environmental protection; public behavior, such as participation in political protests and other forms of activism; and private behavior, such as waste separation or energy conservation (Stern et al., 1999; Kaiser et al., 2003; Iwata, 2004; Mobley et al., 2009; Bratt et al., 2015).

In contrast to these general environmental behavior scales, other instruments have been developed that focus on environmental behavior that has a significant impact on various environmental aspects (see Table 2.1). The behavioral domains of these impact scales are more closely related to the main emission-related sectors. For example, all these scales include the domains of housing and mobility. However, other domains are omitted and some behaviors have even here only minor $\mathrm{CO}_{2}$ relevance. Some 
scales, for example, ask for precise information on water consumption, a behavior that is particularly relevant in areas with water shortages. However, in the emissions inventory in Austria, water and its disposal are only of limited relevance, accounting for about $1 \%$ of all emissions (Bird et al., 2017).

Furthermore, it appears that some items are not suitable for estimating emissions and the frequency of behavior although they aim to measure the environmental impact. Markle's items (2013) on the frequency of switching off lights, reducing heating temperatures, or shortening showering time provide information on how environmentally conscious a person is trying to behave, but do not tell us how much energy is actually consumed as actual consumption is not captured.

When trying to move away from emissions-related behavior to the total emissions generated by an individual's lifestyle across all areas, one must be careful. In general, one's individual emission level is a practically unmeasurable quantity. Even if, as is often the case, technical aids such as smart meters for power consumption or GPS tracking for car use are employed, the actual emissions remain unclear to a certain extent. If you look at the use of a product from a life-cycle perspective, you must also add the emissions released in the past during the extraction of raw materials, production, and transport. A carefully conducted life-cycle assessment (see Chap. 3), however, is able to approximate the output, which in turn can be used for further evaluations and analyses.

\subsection{Survey Programs Considering Environmental Attitudes And Behaviors}

An increased focus on the environmental issue can be found in international survey research, such as the International Social Survey Programme (ISSP), the World Value Survey, the European Social Survey (ESS), and other initiatives as well. Most international surveys, such as ISSP 2010 and ESS 2016, have treated behavioral aspects in a similar way. A closer look at these scales shows that behaviors associated with only relatively low $\mathrm{CO}_{2}$ emissions, such as waste separation, are prominently surveyed. The reason for the inclusion of such behaviors may partly be that they are seen as indicators of a general positive attitude toward the environment, reflecting environmental awareness. There are six items on environmental personal behavior in the ISSP 2010 measured via statements rated on a four-point 
scale, ranging from "always" to "never." Two of them ask whether someone makes "a special effort" to recycle and buy organic. The other four statements include the phrase "for environmental reasons" when asking about behaviors. On the one hand, these features are likely to assure a higher level of internal consistency; on the other hand, it shifts the focus toward the intention and thus away from the impact perspective.

Environmental attitudes, alternatively, have been surveyed intensively in these international programs. The ISSP first surveyed a pool of questions on this topic in 1993, which was also the central focus in 2000, 2010 , and 2020 (Gesis, 2020). The questionnaires cover aspects such as salience of environmental issues, environmental knowledge, attitudes toward environment, science and nature, the willingness to make tradeoffs for the environment, environmental efficacy respectively skepticism, the assessment of dangers of environmental problems, and attitudes toward environmental policies. The sub-dimension of attitudes toward the environment, science, and nature includes items related to the environment/science relationship, attitudes toward economic growth and modern lifestyles. The World Value Survey fielded questions on environmental awareness in the second, fourth, and fifth waves of the survey (World Value Survey, 2020), dealing with the willingness to make trade-offs in order to avoid pollution and with an assessment of the dangers of environmental problems for the local and, separately, for the global environment.

The ESS treated behavioral aspects in a similar way. It dealt with the topic of climate change and energy use for the first time in 2016 in Round 8 (ESS, 2020). Regarding attitudes, the questionnaire included items on preferred method of energy production, belief in climate change, an assessment of the consequences and causes of climate change, and preferred method of tackling the causes. The Eurobarometer surveys have dealt already several times with the attitudes of the European population toward environmental issues. Since 1999, thematic survey waves have been conducted in this area (environment, biodiversity, climate change, and sustainability) regularly (Eurobarometer, 2020). The specific dimensions that have been surveyed cover a wide range of topics, including the classification of environmental hazards and the personal importance of environmental protection and personal responsibility, intentions, environmental influence on the quality of life, environmental knowledge, and the assessment of the role of political actors when it comes to environmental protection. 
Given the increasing importance of climate change, research has started to focus more on this topic. As mentioned before, the ESS fielded a module on this topic in 2016, and the ISSP included some questions on this topic in its 2020 module. Alongside these large international groups, several other initiatives were active. To gain insight into the perceptions of climate change and policy measures to address it, Steentjes et al. (2017) conducted a cross-national survey, called "European Perceptions of Climate Change (EPCC)," in Germany, Norway, England, and France on the perception of the climate crisis as well as the acceptance of different policy measures. The H2020 project ECHOES (https://db.echoesproject.eu/echoes/home) conducted an online survey in 31 European countries (Reichl et al., 2019) that included numerous questions on climate-relevant behaviors and some questions on lifestyle indicators and socio-demographics. Two of the authors of the current book, Neil Bird and Stephan Schwarzinger, were members of the ECHOES team and will use its data.

\subsection{COnclusions And Outlook}

This chapter provided an overview of the theoretical approaches to environmental attitudes and behaviors, as well as of different scales and survey programs with a focus on this topic. In general, capturing individual behavior is often problematic. Research on environmental behavior has repeatedly shown that self-reported behavior can be subject to strong biases because actions are assessed inaccurately or because respondents try to present themselves in a rather favorable light (Bratt et al., 2015). In addition, it is problematic that some scales, although only one person is interviewed, target the household level (Bohunovsky et al., 2011; Gatersleben et al., 2002; Huddart Kennedy et al., 2015) and are prone to considerable deviations (Grønhøj \& Ölander, 2007; Seebauer et al., 2017).

The scales presented in this section have rarely been compared with external criteria. In many cases, validity was checked with reference to the correlation of the dimensions among each other (Armel et al., 2011) or to the correlation with attitude and value scales (Huddart Kennedy et al., 2015; Markle, 2013). Positive exceptions are Gerhard Bodenstein et al. (1997) and Brigitta Gatersleben et al. (2002), who compare the calculated energy consumption with official energy numbers or data from representative studies. However, since in both cases only the mean value of their own 
samples is compared with average values, specific assessments of the validity of different individual scales and items are not possible.

A validation of self-reports by means of external criteria through observations of the behavioral consequences by the interviewers was carried out with a general environmental behavior scale, called the "General Ecological Behavior Scale," by Florian Kaiser et al. (2003), listed in Table 2.1. Kaiser, together with Jacqueline Frick and Susanne Stoll-Kleemann (2001), was able to show that the subjective behavioral data corresponded well with the observations. However, only those items that could be well observed were specifically selected, such as the possession of clothing made of natural fibers, of energy-saving lamps, or of a solar energy system. Therefore, it is difficult to draw conclusions about the validity of less easily observable behaviors with a greater environmental impact.

We will add to this research by validating our impact scales with different external criteria. The results are presented in Chap. 5. Beforehand, the following Chap. 3 will identify the relevant segments of social life that produce GHG and show how the emissions and energy demand of these behaviors can be estimated.

\section{REFERENCES}

Abrahamse, W., \& Steg, L. (2009). How do socio-demographic and psychological factors relate to households' direct and indirect energy use and savings? Journal of Economic Psychology, 30(5), 711-720.

Ajzen, I. (1991). The theory of planned behavior. Organizational Behavior and Human Decision Processes, 50(2), 179-211.

Armel, K. C., Yan, K., Todd, A., \& Robinson, T. N. (2011). The Stanford Climate Change Behavior Survey (SCCBS). Assessing greenhouse gas emissions-related behaviors in individuals and populations. Climatic Change, 109(3-4), 671-694.

Bamberg, S., \& Möser, G. (2007). Twenty years after Hines, Hungerford, and Tomera: A new meta-analysis of psycho-social determinants of proenvironmental behaviour. Journal of Environmental Psychology, 27(1), 14-25.

Benders, R. M. J., Kok, R., Moll, H. C., Wiersma, G., \& Noorman, K. J. (2006). New approaches for household energy conservation: In search for personal household energy budgets and energy education options. Energy Policy, 34, $3612-3622$.

Best, H. (2011). Methodische Herausforderungen: Umweltbewusstsein, Feldexperimente und die Analyse umweltbezogener Entscheidungen. In M. Groß (Ed.), Handbuch Umweltsoziologie. VS Verlag für Sozialwissenschaften. 
Bird, N., Jungmeier, G., Canella, L., Windsperger, B., \& Windsperger A. (2017). Consumption based accounting using LCA. Stakeholder dialog meeting.

Blake, J. (1999). Overcoming the 'value-action gap' in environmental policy: Tensions between national policy and local experience. Local Environment, 4(3), 257-278.

Bodenstein, G., Spiller, A., \& Elbers, H. (1997). Strategische Konsumentscheidungen: Langfristige Weichenstellungen für das Umwelthandeln-Ergebnisse einer empirischen Studie. Diskussionsbeiträge des Fachbereichs Wirtschaftswissenschaft der Gerhard-Mercator-Universität-Gesamthochschule-Duisburg.

Bohunovsky, L., Grünberger, S., Frühmann, J., \& Hinterberger, F. (2011). Energieverbrauchsstile. Datenbank zum Energieverbrauch österreichischer Haushalte: Erstellung und empirische Überprïfung. Sustainable Europe Research Institute.

Bord, R. J., O'connor, R. E., \& Fisher, A. (2000). In what sense does the public need to understand global climate change? Public Understanding of Science, 9, 205-218.

Bratt, C., Stern, P. C., Matthies, E., \& Nenseth, V. (2015). Home, Car Use, and Vacation. Environment and Behavior, 47(4), 436-473.

Catton, W. R., Jr., \& Dunlap, R. E. (1978). Environmental sociology: A new paradigm. The American Sociologist, 13(1), 41-49.

Christakis, N. A., \& Fowler, J. H. (2007). The spread of obesity in a large social network over 32 years. New England Journal of Medicine, 357(4), 370-379.

Csutora, M. (2012). One more awareness gap? The behaviour-impact gap problem. Journal of Consumer Policy, 35(1), 145-163.

Diekmann, A., \& Jann, B. (2000). Sind die empirischen Ergebnisse zum Umweltverhalten Artefakte? Ein Beitrag zum Problem der Messung von Umweltverhalten. Umweltpsychologie, 4(1), 64-75.

Diekmann, A., \& Preisendörfer, P. (1998). Umweltbewußtsein und Umweltverhalten in Low-und High-Cost-Situationen: Eine empirische Überprüfung der Low-Cost-Hypothese. Zeitschrift für Soziologie, $27(6), 438-453$.

Dunlap, R. E., \& Jones, R. E. (2002). Environmental concern: Conceptual and measurement issues. Handbook of Environmental Sociology, 3(6), 482-524.

Dunlap, R. E., \& Van Liere, K. D. (1978). The 'new environmental paradigm'. The Journal of Environmental Education, 9(4), 10-19.

Dunlap, R. E., Van Liere, K. D., Mertig, A. G., \& Jones, R. E. (2000). New trends in measuring environmental attitudes: Measuring endorsement of the new ecological paradigm: A revised NEP scale. Journal of Social Issues, 56(3), 425-442. Ehrhardt-Martinez, K., Schor, J. B., Abrahamse, W., Alkon, A., Axsen, J., Brown, K., Shwom, R., Southerton, D., \& Wilhite, H. (2015). Consumption and 
climate change. In R. E. Dunlap \& R. J. Brulle (Eds.), Climate change and society: Sociological perspectives (pp. 93-126). Oxford University Press.

Eurobarometer. (2020). Eurobarometer surveys on public attitudes to the environment. Retrieved October 8, 2020, from https://ec.europa.eu/environment/eurobarometers_en.htm

European Social Survey. (2020). Data and documentation by round/year. Retrieved October 2, 2020, from https://www.europeansocialsurvey.org/ data/round-index.html

Fairbrother, M. (2013). Rich people, poor people, and environmental concern: Evidence across nations and time. European Sociological Review, 29(5), 910-922.

Gatersleben, B., Steg, L., \& Vlek, C. (2002). Measurement and determinants of environmentally significant consumer behavior. Environment and Behavior, $34(3), 335-362$.

Gesis. (2020). Environment. Retrieved October 2, 2020, from https://www. gesis.org/en/issp/modules/issp-modules-by-topic/environment

Gifford, R., \& Sussman, R. (2012). Environmental attitudes. In S. D. Clayton (Ed.), The Oxford handbook of environmental and conservation psychology. Oxford University Press.

Grønhøj, A., \& Ölander, F. (2007). A gender perspective on environmentally related family consumption. Journal of Consumer Behaviour: An International Research Review, 6(4), 218-235.

Hadler, M., \& Haller, M. (2011). Global activism and nationally driven recycling: The influence of world society and national contexts on public and private environmental behavior. International Sociology, 26(3), 315-345.

Hawcroft, L. J., \& Milfont, T. L. (2010). The use (and abuse) of the new environmental paradigm scale over the last 30 years: A meta-analysis. Journal of Environmental Psychology, 30(2), 143-158.

Huddart Kennedy, E., Krahn, H., \& Krogman, N. T. (2015). Are we counting what counts? A closer look at environmental concern, pro-environmental behaviour, and carbon footprint. Local Environment, 20(2), 220-236.

Inglehart, R. (1997). Modernization and postmodernization: Cultural, economic, and political change in 43 societies. Princeton University Press.

Iwata, O. (2004). Some psychological correlates of environmentally responsible behavior. Social Behavior and Personality, 32(8), 703-714.

Kaiser, F. G., Frick, J., \& Stoll-Kleemann, S. (2001). On the adequacy of self reported behavior. A study of the validity of the general ecological behavior scale. Diagnostica, 47, 88-95.

Kaiser, F. G., Doka, G., Hofstetter, P., \& Ranney, M. A. (2003). Ecological behavior and its environmental consequences. A life cycle assessment of a self-report measure. Journal of Environmental Psychology, 23(1), 11-20. 
Klineberg, S. L., McKeever, M., \& Rothenbach, B. (1998). Demographic predictors of environmental concern: It does make a difference how it's measured. Social Science Quarterly, 79(4), 734-753.

Knight, K. W., \& Messer, B. L. (2012). Environmental concern in cross-national perspective: The effects of affluence, environmental degradation, and world society. Social Science Quarterly, 93(2), 521-537.

Kollmuss, A., \& Agyeman, J. (2002). Mind the gap: Why do people act environmentally and what are the barriers to pro-environmental behavior? Environmental Education Research, 8(3), 239-260.

Lenzen, M., Dey, C., \& Foran, B. (2004). Energy requirements of Sydney households. Ecological Economics, 49(3), 375-399.

Maloney, M. P., \& Ward, M. P. (1973). Ecology: Let's hear from the people: An objective scale for the measurement of ecological attitudes and knowledge. American Psychologist, 28(7), 583-586.

Markle, G. L. (2013). Pro-environmental behavior: Does it matter how it's measured? Development and validation of the pro-environmental behavior scale (PEBS). Human Ecology, 41(6), 905-914.

Marquart-Pyatt, S. T. (2008). Are there similar sources of environmental concern? Comparing industrialized countries. Social Science Quarterly, 89(5), 1312-1335.

Mobley, C., Vagias, W. M., \& DeWard, S. L. (2009). Exploring additional determinants of environmentally responsible behavior. The influence of environmental literature and environmental attitudes. Environment and Behavior, $42(4), 420-447$.

Newton, P., \& Meyer, D. (2012). The determinants of urban resource consumption. Environment and Behavior, 44(1), 107-135.

Perkins, D. N., Drisse, M. N. B., Nxele, T., \& Sly, P. D. (2014). E-waste: A global hazard. Annals of Global Health, 80(4), 286-295.

Pisano, I., \& Lubell, M. (2017). Environmental behavior in cross-national perspective: A multilevel analysis of 30 countries. Environment and Behavior, $49(1), 31-58$.

Poortinga, W., Steg, L., \& Vlek, C. (2004). Values, environmental concern, and environmental behavior: A study into household energy use. Environment and Behavior, 36(1), 70-93.

Reichl, J., Cohen, J., Kollmann, A., Azarova, V., Klöckner, C., Royrvik, J., Vesely, S., Carrus, G., Panno, A., Tiberio, L., Fritsche, I., Masson, T., Chokrai, P., Lettmayer, G., Schwarzinger, S., \& Bird, N. (2019). International survey of the ECHOES project. Dataset. Zenodo. https://doi.org/10.5281/ zenodo. 3524917

Samdahl, D. M., \& Robertson, R. (1989). Social determinants of environmental concern: Specification and test of the model. Environment and Behavior, $21(1), 57-81$. 
Schaffrin, A. (2011). No measure without concept: A critical review on the conceptualization and measurement of environmental concern. International Review of Social Research, 3, 11-31.

Schwartz, S. H. (1977). Normative influences on altruism. Advances in Experimental Social Psychology, 10, 221-279.

Seebauer, S., Fleiß, J., \& Schweighart, M. (2017). A household is not a person: Consistency of pro-environmental behavior in adult couples and the accuracy of proxy-reports. Environment and Behavior, 49(6), 603-637.

Steentjes, K., Pidgeon, N., Poortinga, W., Corner, A., Arnold, A., Boehm, G., Mays, C., Poumadère, M., Ruddat, M., Scheer, D., Sonnberger, M., \& Tvinnereim, E. (2017). European Perceptions of Climate Change (EPCC): Topline findings of a survey conducted in four European countries in 2016. Cardiff: Cardiff University. https://orca.cardiff.ac.uk/98660/7/EPCC.pdf

Stern, P. C. (2000). New environmental theories: Toward a coherent theory of environmentally significant behavior. Journal of Social Issues, 56(3), 407-424.

Stern, P. C. (2011). Contributions of psychology to limiting climate change. American Psychologist, 66(4), 303-314.

Stern, P. C., Dietz, T., Abel, T., Guagnano, G. A., \& Kalof, L. (1999). A valuebelief-norm theory of support for social movements: The case of environmentalism. Human Ecology Review, 6(2), 81-97.

Tabi, A. (2013). Does pro-environmental behaviour affect carbon emissions? Energy Policy, 63, 972-981.

Van Liere, K. D., \& Dunlap, R. E. (1981). Environmental concern: Does it make a difference how it's measured? Environment and Behavior, 13(6), 651-676.

World Value Survey. (2020). Retrieved October 2, 2020, from https://www. worldvaluessurvey.org/WVSContents.jsp

Wynes, S., \& Nicholas, K. A. (2017). The climate mitigation gap: Education and government recommendations miss the most effective individual actions. Environmental Research Letters, 12(7), 074024.

Zelezny, L. C., Chua, P. P., \& Aldrich, C. (2000). New ways of thinking about environmentalism: Elaborating on gender differences in environmentalism. Journal of Social Issues, 56(3), 443-457. 
Open Access This chapter is licensed under the terms of the Creative Commons Attribution 4.0 International License (http://creativecommons.org/licenses/ by $/ 4.0 /$ ), which permits use, sharing, adaptation, distribution and reproduction in any medium or format, as long as you give appropriate credit to the original author(s) and the source, provide a link to the Creative Commons licence and indicate if changes were made.

The images or other third party material in this chapter are included in the chapter's Creative Commons licence, unless indicated otherwise in a credit line to the material. If material is not included in the chapter's Creative Commons licence and your intended use is not permitted by statutory regulation or exceeds the permitted use, you will need to obtain permission directly from the copyright holder. 